\title{
CANFOR Portuguese version: validation study
}

\author{
Miguel Talina ${ }^{1 *}$, Stuart Thomas², Ana Cardoso ${ }^{1}$, Pedro Aguiar ${ }^{3}$, Jose M Caldas de Almeida ${ }^{1}$ and Miguel Xavier ${ }^{1}$
}

\begin{abstract}
Background: The increase in prisoner population is a troublesome reality in several regions of the world. Along with this growth there is increasing evidence that prisoners have a higher proportion of mental illnesses and suicide than the general population. In order to implement strategies that address criminal recidivism and the health and social status of prisoners, particularly in mental disordered offenders, it is necessary to assess their care needs in a comprehensive, but individual perspective. This assessment must include potential harmful areas like comorbid personality disorder, substance misuse and offending behaviours. The Camberwell Assessment of Need Forensic Version (CANFOR) has proved to be a reliable tool designed to accomplish such aims. The present study aimed to validate the CANFOR Portuguese version.

Methods: The translation, adaptation to the Portuguese context, back-translation and revision followed the usual procedures. The sample comprised all detainees receiving psychiatric care in four forensic facilities, over a one year period. A total of 143 subjects, and respective case manager, were selected. The forensic facilities were chosen by convenience: one prison hospital psychiatric ward $(n=68 ; 47.6 \%)$, one male $(n=24 ; 16.8 \%)$ and one female $(n=22$; 15.4\%) psychiatric clinic and one civil security ward $(n=29 ; 20.3 \%)$, all located nearby Lisbon. Basic descriptive statistics and Kappa weighted coefficients were calculated for the inter-rater and the test-retest reliability studies. The convergent validity was evaluated using the Global Assessment of Functioning and the Brief Psychiatric Rating Scale scores.

Results: The majority of the participants were male and single, with short school attendance, and accused of a crime involving violence against persons. The most frequent diagnosis was major depression (56.1\%) and almost half presented positive suicide risk. The reliability study showed average Kappa weighted coefficients of 0.884 and 0.445 for inter-rater and test-retest agreement, respectively. The convergent validity study presented highly significant correlations between unmet needs scores, GAF and BPRS scores.

Conclusions: The CANFOR Portuguese version revealed similar psychometric properties to the original English version. Moreover, the results of the reliability and validity studies indicate that the tool is appropriate for individual care needs assessment and as a guide for the mental health and social interventions in forensic psychiatric services.
\end{abstract}

Keywords: Forensic psychiatry, Needs assessment, Mental disorders, Mentally disordered offenders, Prisoners, Prison

\section{Background}

The growth of the prison population along with the increasing number of prisoners with mental disorders is one of the great concerns of the political and health authorities [1]. Review of 63 mental morbidity prevalence studies shows that one out of every seven prisoners $(14.3 \%)$ in the western countries has a psychotic disorder or major depression [2]. In Europe, a study on mental disturbances in prisons of thirteen countries revealed

\footnotetext{
* Correspondence: miguel.talina@fcm.unl.pt

'CEDOC, Faculdade de Ciências Médicas, Universidade Nova de Lisboa, Campo Mártires da Pátria, Lisbon 1169-056, Portugal

Full list of author information is available at the end of the article
}

that about five per cent of the prisoners met criteria for a psychotic disorder and about one in four presented an affective or anxiety disorder. When including those with drug abuse, $63 \%$ of them met criteria for a mental disorder [3]. These rates are significantly higher than those found in the community. According to Reed [4], the reasons for this high prevalence include higher risk of arrest for people with mental disorders alleged to have offended, inadequate coverage by court assessment schemes, too few psychiatric beds, and poor identification of mental disorders during the prison reception process. On the other hand, there are many factors in prisons that can have deleterious effects on mental

\section{Biomed Central}


health, including: overcrowding, various forms of violence, enforced solitude, or, conversely, lack of privacy, lack of meaningful activity, isolation from social networks, insecurity about future prospects (work, relationships, etc.), and inadequate health services in prisons, especially mental health services. The increased risk of suicide in prisons - often related to depression - is, unfortunately, one common manifestation of the cumulative effects of these factors [5]. Therefore, it is not surprising that mental health care needs are very high and represent a significant on-going challenge for service providers [2,3]. Nowadays there is broad consensus of the importance of addressing the needs of care of the mentally disordered offenders (MDOs), who, like the whole prison population, have higher proportions of medical and social problems compared to the community population and are subject to some form of social exclusion [2,6-9]. Whilst the social and clinical needs of MDOs are in many ways similar to those of general psychiatric patients, there are also differences that must be assessed. In particular, more emphasis must be placed on certain areas such as co-morbid personality disorder, substance misuse and offending behaviours $[10,11]$.

There are several instruments developed to measure individual needs in general psychiatric populations. The Camberwell Assessment of Need (CAN) [12] is one of the most frequently used and potentially valuable tools for this purpose [13]. In order to acknowledge the differences between civil and forensic psychiatric populations, Thomas and colleagues developed a version based on the structure of CAN that was targeted to the forensic mental health service users: the Camberwell Assessment of Need - forensic version (CANFOR) [14]. The CANFOR maintain the same 22 domains of CAN plus three new domains related to treatment acquiescence and offending behaviour: "Treatment", "Sexual Offences" and "Arson". There are three versions of the published tool (the Research, Clinical and Short Versions) as well as a training manual [15].

\section{The situation in Portuguese prisons}

The Portuguese prison system is administered by the General-Directorate of Prison Services, an organization that depends on the Ministry of Justice. There are 56 prison facilities throughout the territory, with near 12,000 places. As in many other countries, the number of prisoners has increased steadily over the last decades. Since 1974 (prison population: 2,519) the number of prisoners has increased more than 4.5 times [16]. At the beginning of the 70s, Portugal had one of the highest rates of prisoners in Western Europe: 132.8 per 100,000 inhabitants $[17,18]$. However, in recent years, the rate of prison population per 100,000 inhabitants has decreased, standing at 104.4 in 2009 [19]. This ratio places Portugal at the medium ranking in the European context. In addition, prison overcrowding (120.7 prisoners per 100 places, in 2002) has been decreasing since then; the occupancy rate in 2009 was $93.1 \%$ [16].

In accordance with the Portuguese law, offenders found not guilty by reason of insanity (non-imputable) and considered at risk of re-offending are sentenced to a security measure in which they are admitted to a security psychiatric ward, either in prison or in the public health system. They are included in the total prison population, although their number is usually small (157 individuals in 2009) [16].

In the year 2009, the prison population was 11,099 individuals, and sentenced prisoners accounted for $80.7 \%$. The average age of prisoners was 37.8 years, which represents an ageing of four years since 2000 . Young prisoners (16-20 years-old) and prisoners over 60 years-old made up 3\% and 3.4\% of the total population, respectively. Interestingly, the proportion of women detained has been decreasing since the year 2000, when it stood at $9.2 \%$. It now stands at $5.4 \%$. This trend may be due to a decrease in the number of prison sentences related to drug trafficking and an increase in the number of prison sentences related to crimes against persons.

On the other hand, the proportion of immigrants or foreigners in the prison population has been increasing, reaching one-fifth of the total in 2009 [16].

Nowadays, most prison sentences are related to crimes against property (30.5\%) followed by crimes against persons (29.4\%) and crimes linked to drug trafficking (22.7\%). Almost half of the prisoners (49.4\%) were sentenced from three to nine years of imprisonment. Prison sentences of fewer than three and more than nine years accounted for $24.7 \%$ and $23 \%$ of prisoners, respectively [16].

Healthcare in the prison system is a direct responsibility of the General-Directorate of Prison Services. In-patient care is delivered by one major prison-hospital located near Lisbon and small-size wards located in larger prisons around the national territory. Whenever the level of healthcare needed exceeds the specialization of the prison health services (e.g. intensive care, neurosurgery), prisoners are admitted to National Health Service facilities. In general, however, healthcare is delivered in each prison facility (e.g. general practice, psychiatry, nursing, dentistry), and there is an administrative policy to contract healthcare services and staff from private companies. Mental health care is mainly delivered on an "out-patient" basis at the prison facilities, and in-patient admissions are effected in two psychiatric wards, one at S. João de Deus PrisonHospital (HPSJD), located near Lisbon, and the other at Santa Cruz do Bispo Prison, in Oporto. These facilities hold 28 and 12 beds, respectively.

An existing analysis of various surveys shows that prisoners at prison entry display high levels of morbidity, 
particularly communicable diseases (HIV, viral hepatitis and tuberculosis), and addictions to drugs. Addictions, suicide and mental health disorders are the major health problems, but, aside from data on drug abuse, the mental health status of Portuguese prisoners remains still largely unknown [20,21].

A recent study, including 10,182 prisoners, concluded that $40 \%$ were drug abusers and of these, half take more than one drug. Cannabis was the most frequent substance of abuse (52.5\%), 31.8\% of prisoners used cocaine intravenously, and 30.5\% abused heroin [20].

For drug addiction treatment, there are seven free drug wings located in several prisons across the territory. In these special units the treatment programme aims at abstinence and lasts eighteen months on average. The programme incorporates educational, occupational and therapeutic activities. Drug addicted prisoners can also be treated at the public facilities belonging to the Drug Addiction Institute (IDT), such as therapeutic communities or outpatient clinics [21].

Over the last fourteen years suicide death rates in Portuguese prisons have fluctuated between seven and 23 deaths per year, with an average of 14.7 a year, and 11 per 10,000 prisoners. The mean suicides/overall mortality ratio is $0.185(18.5 \%)$. Notwithstanding, the overall mortality rate has been decreasing steadily [21]. According to European statistics, in the period of 2002-2006, France ranked first, with a suicide death rate of 20 per 10,000 prisoners, and Portugal was fourth (12/10,000 prisoners). Between the two were Denmark (13.5/10,000 prisoners) and Belgium (13/10,000 prisoners) [22]. However, when the suicide rate per prisoner entries per year is calculated, the ranking position changes and Portugal becomes the leader with a rate of eight suicide deaths per 10,000 prisoners admitted per year. Another relevant calculation takes into account the suicide rate of the general population in each country and measures the excess suicide deaths in prison compared to the national rate. Again, Portugal shows one of the highest excess of suicide deaths in prison (prison/non-prison ratio of suicide rates: 8), only outranked by Italy (prison/non-prison ratio of suicide rates: 9) [22].

Given the absence of reliable forensic mental health needs assessment tools validated for the Portuguese language, the validation of the CANFOR-Research Version is a relevant step towards the improvement of care for MDOs in our country.

\section{Methods}

\section{Translation and back-translation procedures}

The validation procedure started with the complete translation of the English research version of CANFOR into the Portuguese language. A focus group from the psychiatric ward staff of a prison-hospital (HPSJD) was organized in order to adapt the translated version to the contextual and cultural setting of Portugal. This focus group comprised five psychiatrists, two nurses, one psychologist, and one social worker. A brief pilot-study with five opportunistic interviews to prisoners admitted at psychiatric ward was then performed to check comprehension of the questions. Finally, the corrected version was back-translated into English and checked for consistency by the first author of the original version.

\section{Participants}

All individuals receiving care in four different forensic psychiatric facilities (forensic psychiatric services users FPSUs) over a one year period (May 2009-May 2010) were selected. The forensic services, chosen by convenience in the Greater Lisbon region, were composed of: the psychiatric ward of a prison-hospital (28 beds with a median stay of 27 days - HPSJD), two psychiatric "outpatient" clinics (one in a male prison, Caxias Prison, and one in a female prison, Tires Prison, with 390 male and 425 female prisoners, respectively), and a civil security psychiatric ward for non-imputable offenders (31 beds in Hospital Miguel Bombarda (HMB)).

Due to circumstantial reasons, not all FPSUs participated in inter-rater and test-retest reliability procedures. As a result, there are differences between the participant numbers (n) in inter-rater, test-retest and convergent studies. All the participants signed the consent form.

\section{Evaluation instruments}

The following instruments were included in the research protocol: a socio-demographic questionnaire designed specifically for this study; the Mini International Neuropsychiatric Interview 5.0.0 (MINI) [23], which was already in use in the prison population [24] and was included in order to validate the diagnosis using DSM-IV [25]; the Brief Psychiatric Rating Scale 4.0 (BPRS) [26], an extensively used tool to assess psychopathology; the Global Assessment of Functioning (GAF) - disability scale [27], in order to assess the level of the participants' psychosocial functioning, in accordance with prior validating studies $[14,28]^{\text {' }}$ and finally, the CANFOR - Portuguese research version.

\section{Inter-rater and test-retest reliability}

Both the inter-rater and test-retest reliability studies were performed by two researchers (MT and AC). Interrater reliability was tested by simultaneous scoring: while one researcher conducted the interview and scored the CANFOR domains, the second one sat silently in the room and scored the CANFOR independently. The researchers' roles alternated in consecutive interviews. A total of ninety-six FPSUs were scored using this procedure. In order to study the test-retest reliability a second 
CANFOR scoring was carried out after one to two weeks by the same researcher who had performed the first scoring. A total of ninety-nine FPSUs were scored using this procedure.

\section{Convergent validity}

The convergent validity of CANFOR was studied using two instruments: the GAF - disability scale, and the BPRS. The GAF - disability scale, is rated from 10 to 100 (from lowest to highest psychosocial functioning) while the BPRS`s 22 scales of psychopathological symptoms and signs are rated between 1 (not present) and 7 (extremely severe).

\section{Statistical analysis}

Basic descriptive statistics were used to describe the socio-demographic, clinical and forensic characteristics of the sample.

In the studies of inter-rater and test-retest reliability, the Kappa weighted coefficient was calculated for the three values of need status (no need, met need and unmet need) from the first section of CANFOR $[29,30]$. In order to minimise empty cells in the tables necessary for Kappa calculation, the scores "8-not applicable" and "9unknown" were considered missing values. According to Landis and Koch [31], a Kappa coefficient of 0.4 to 0.6 indicates a moderate grade of agreement, between 0.6 and 0.8 indicates significant agreement, and between 0.8 and 1 almost perfect agreement.

The differences between CANFOR summary scores rated by FPSUs and staff were tested with Paired $t$ test.

Convergent validity between CANFOR total scores and the GAF disability scale, and CANFOR domains and BPRS scales were considered using non-parametric tests (Spearman correlation and Mann-Whitney test, respectively) due to the data being skewed. All data were analysed using the Statistical Package for the Social Sciences (SPSS) for Windows, version 17.0.0 and GraphPad Software (http://graphpad.com/quickcalcs/kappa1/).

\section{Ethics approval}

The research project was approved by the GeneralDirectorate of Prison Services, Ministry of Justice and the Scientific Board of Faculty of Medical Sciences, New University of Lisbon.

\section{Results}

\section{Participant characteristics}

A total of 143 subjects, and respective case manager, were recruited. The FPSUs belonged to the following facilities: $68(47.6 \%)$ from the prison psychiatric ward, 24 (16.8\%) from the male psychiatric clinic, 22 (15.4\%) from the female psychiatric clinic, and 29 (20.3\%) from the civil security ward. A total of 38 (30\%) subjects (36 from the prison hospital and 2 from the civil security ward) were not included mainly due to discharge, cognitive impairment or refusal (Table 1).

Males constituted the predominant gender of the sample. Almost half of the sample came from the psychiatric ward of the prison hospital and the majority were Portuguese citizens, were single and had attended a maximum of six years of education.

Around eighty per cent of the sample were convicted prisoners or on remand and twenty per cent were NGRI individuals detained in a civil security ward by court decision. The majority of the FPSUs (59.4\%) were accused of an "offence against persons", which includes all crimes involving violence against persons. The category "offences against property" includes crimes against material possessions, not involving violence. Almost half of the sample (49.7\%) had previously been convicted and one

Table 1 Socio-demographic characteristics of the FPSUs

\begin{tabular}{|c|c|c|}
\hline & Socio-demog & \\
\hline$(n=143)$ & $\mathbf{n}$ & $\%$ \\
\hline \multicolumn{3}{|l|}{ Gender } \\
\hline Males & 108 & 75.5 \\
\hline Females & 35 & 24.5 \\
\hline \multicolumn{3}{|l|}{ Age (mean \pm s.d.) } \\
\hline Males & $39.7 \pm 12.78$ & \\
\hline Females & $35.2 \pm 9.98$ & \\
\hline \multicolumn{3}{|l|}{ Origin } \\
\hline Prison-Hospital ${ }^{1}$ & 68 & 47.6 \\
\hline Male prison $^{2}$ & 24 & 16.8 \\
\hline Female prison ${ }^{3}$ & 22 & 15.4 \\
\hline Civil security unit ${ }^{4}$ & 29 & 20.3 \\
\hline \multicolumn{3}{|l|}{ Nationality } \\
\hline Portuguese & 112 & 78.3 \\
\hline Portuguese speaking country & 21 & 14.7 \\
\hline European country & 7 & 4.9 \\
\hline Other & 3 & 2.1 \\
\hline
\end{tabular}

\begin{tabular}{lll}
\hline Civil status & 92 & \\
\hline Single & 26 & 64.3 \\
\hline Married or equivalent status & 19 & 18.2 \\
\hline Divorced & 6 & 13.3 \\
\hline Widowed & & 4.2 \\
\hline School years & 20 & 14.0 \\
\hline$<4$ years & 44 & 30.8 \\
\hline 4 years & 23 & 16.1 \\
\hline 6 years & 31 & 21.7 \\
\hline 9 years & 19 & 13.3 \\
\hline 12 years & 6 & 4.2 \\
\hline University &
\end{tabular}

${ }^{1}$ Hospital Prisional S. João de Deus; ${ }^{2}$ Estabelecimento Prisional de Caxias;

${ }^{3}$ Estabelecimento Prisional de Tires; ${ }^{4}$ Hospital Miguel Bombarda. 
Table 2 Forensic and clinical data of the FPSUs

\begin{tabular}{|c|c|c|}
\hline \multirow[b]{2}{*}{$(n=143)$} & \multicolumn{2}{|c|}{$\begin{array}{l}\text { Forensic and } \\
\text { clinical data }\end{array}$} \\
\hline & $\mathrm{n}$ & $\%$ \\
\hline \multicolumn{3}{|l|}{ Judicial status } \\
\hline \multicolumn{3}{|l|}{ Prisoners } \\
\hline Convicted & 77 & 53.8 \\
\hline On Remand & 37 & 25.9 \\
\hline NGRI*, security measure & 29 & 20.3 \\
\hline \multicolumn{3}{|l|}{ Actual offence } \\
\hline Offences against persons & 85 & 59.4 \\
\hline Offences against property & 32 & 22.4 \\
\hline Other & 26 & 18.2 \\
\hline \multicolumn{3}{|l|}{ Prior judicial history } \\
\hline No convictions & 71 & 49.7 \\
\hline Suspended sentence & 18 & 12.6 \\
\hline Sentenced to prison & 50 & 35.0 \\
\hline Security measure & 3 & 2.1 \\
\hline Unknown & 1 & 0.7 \\
\hline \multicolumn{3}{|l|}{ Number of prior convictions } \\
\hline One & 8 & 5.6 \\
\hline 2 to 5 & 48 & 33.6 \\
\hline more than 5 & 15 & 10.5 \\
\hline Referral reasons for prisoners** & & \\
\hline Psychopathology & 87 & 76.3 \\
\hline Danger to self & 47 & 41.2 \\
\hline Danger to others & 26 & 22.8 \\
\hline Drug withdrawal & 18 & 15.8 \\
\hline Other & 17 & 14.9 \\
\hline MINI diagnostic, current $\quad(n=114)$ & & \\
\hline Major depression & 64 & 56.1 \\
\hline Major depression with melancholic features & 23 & 20.2 \\
\hline Dysthymia & 9 & 7.8 \\
\hline Suicide risk & 50 & 43.9 \\
\hline Mania, Hypomania & 11 & 9.6 \\
\hline Panic disorder & 10 & 8.8 \\
\hline Agoraphobia & 4 & 3.5 \\
\hline Social phobia & 2 & 1.8 \\
\hline Obsessive-compulsive disorder & 5 & 4.4 \\
\hline Posttraumatic stress disorder & 23 & 20.2 \\
\hline Alcohol dependence/abuse & 10 & 8.8 \\
\hline Non-alcohol substance dependence/abuse & 54 & 47.4 \\
\hline Psychotic disorders & 16 & 14.0 \\
\hline Anorexia nervosa & 2 & 1.8 \\
\hline Bulimia nervosa & 16 & 14.0 \\
\hline Generalized anxiety disorder & 52 & 45.6 \\
\hline Antisocial personality disorder, lifetime & 49 & 43.0 \\
\hline
\end{tabular}

${ }^{1}$ Not guilty by reason of insanity. ${ }^{* *}$ One or more referral reasons. third of the participants had received between two and five convictions before the actual sentence (Table 2).

The most common reason for referral to the psychiatric service was assessment of "psychopathological condition" ( $\mathrm{n}=87 ; 76.3 \%)$, and the second most frequent reason was "danger to self" $(\mathrm{n}=47 ; 41.2 \%)$. However, if both "danger to self" and "danger to others" are considered, $64 \%(n=73)$ of FPSUs presented some form of behavioural risk (Table 2).

With regard to the current diagnosis, the most frequent MINI diagnosis was "major depression - current episode" (56.1\%). About one third of these participants were found to show depression with melancholic features, and almost half were found to present positive suicide risk. The second most common diagnosis was "cannabis abuse".

The axis II diagnosis found that $43 \%$ of the FPSUs suffered from anti-social personality disorder.

The CANFOR summary scores, the BPRS and GAF disability scale total scores are described in Table 3. The analysis performed (paired $t$ test and Spearman correlation) of CANFOR summary scores shows that the total of unmet needs obtained from FPSUs and staff ratings are significantly different, although they have a positive significant correlation. By contrast, the average of met needs display an inverse picture: the total scores between FPSUs and staff ratings were almost identical, but they did not correlate with each other. As could be anticipated, the averages of total needs, rated by FPSUs and staff, are significantly different and not correlated.

\section{Inter-rater reliability}

The procedures regarding inter-rater reliability were completed in 96 FPSUs. The inter-rater reliability study showed Kappa weighted coefficients of over 0.8 (almost

Table 3 Instruments` total scores rated by FPSUs and staff

\begin{tabular}{|c|c|c|c|}
\hline & \multicolumn{3}{|c|}{ Instruments' total scores } \\
\hline & mean \pm s.d. & $\begin{array}{l}\text { Paired } \\
t \text { test } \\
\mathrm{p} \text { value }\end{array}$ & $\begin{array}{l}\text { Spearman's } \\
\text { rho } \\
\text { (p value) }\end{array}$ \\
\hline \multicolumn{4}{|l|}{ CANFOR $^{1}(n=143)$} \\
\hline Total needs rated by FPSUs & $7.8 \pm 3.05$ & $<0.001$ & 0.122 \\
\hline Total needs rated by staff & $6.1 \pm 2.90$ & & $(0.145)$ \\
\hline Total met needs rated by FPSUs & $2.5 \pm 1.85$ & 0.926 & -0.030 \\
\hline Total met needs rated by staff & $2.5 \pm 2.08$ & & $(0.722)$ \\
\hline $\begin{array}{l}\text { Total unmet needs rated } \\
\text { by FPSUs }\end{array}$ & $5.2 \pm 2.65$ & $<0.001$ & 0.185 \\
\hline $\begin{array}{l}\text { Total unmet needs rated } \\
\text { by staff }\end{array}$ & $3.6 \pm 2.03$ & & $(0.027)$ \\
\hline $\mathbf{G A F}^{2}(n=143)$ & $46.8 \pm 20.07$ & & \\
\hline $\mathrm{BPRS}^{3}(\mathrm{n}=114)$ & $38.1 \pm 6.85$ & & \\
\hline
\end{tabular}


perfect agreement) in most CANFOR domains. The domains of "Food", "Alcohol" and "Sexual Offences" showed the lowest agreement between raters - between 0.5 and 0.8 (Table 4).

\section{Test-retest reliability}

Test-retest reliability procedures were completed in 99 FPSUs. The average Kappa weighted coefficient was 0.445 (moderate level of agreement). Eight CANFOR domains $(32 \%)$ had Kappa weighted coefficients that fell

Table 4 Inter-rater and Test-retest reliability data

\begin{tabular}{|c|c|c|c|c|}
\hline \multirow[b]{4}{*}{$\begin{array}{l}\text { CANFOR } \\
\text { domains }\end{array}$} & \multirow{3}{*}{\multicolumn{2}{|c|}{$\begin{array}{l}\text { Inter-rater reliability } \\
\mathrm{n}=96 \\
\text { No need, met need, } \\
\text { unmet need scores }\end{array}$}} & \multirow{3}{*}{\multicolumn{2}{|c|}{$\begin{array}{l}\text { Test-retest reliability } \\
\mathrm{n}=99 \\
\begin{array}{l}\text { No need, met need, } \\
\text { unmet need scores }\end{array}\end{array}$}} \\
\hline & & & & \\
\hline & & & & \\
\hline & \multirow[t]{2}{*}{$\%$ agreement } & \multirow{2}{*}{$\begin{array}{l}\text { Kappa } \\
\text { weighted } \\
\text { coefficient }\end{array}$} & \multirow[t]{2}{*}{$\begin{array}{l}\% \\
\text { agreement }\end{array}$} & \multirow{2}{*}{$\begin{array}{l}\text { Kappa } \\
\text { weighted } \\
\text { coefficient }\end{array}$} \\
\hline$(n=99)$ & & & & \\
\hline Accommodation & 100 & 1.000 & 100 & * \\
\hline Food & 75.00 & 0.600 & 75.00 & na \\
\hline $\begin{array}{l}\text { Living } \\
\text { environment }\end{array}$ & 98.67 & 0.917 & 86.44 & 0.276 \\
\hline Self-care & 98.67 & 0.941 & 88.14 & 0.477 \\
\hline $\begin{array}{l}\text { Daytime } \\
\text { activities }\end{array}$ & 81.33 & 0.807 & 55.93 & 0.408 \\
\hline Physical health & 90.67 & 0.873 & 77.97 & 0.661 \\
\hline $\begin{array}{l}\text { Psychotic } \\
\text { symptoms }\end{array}$ & 90.14 & 0.875 & 71.43 & 0.556 \\
\hline Information & 97.33 & 0.974 & 59.32 & 0.369 \\
\hline $\begin{array}{l}\text { Psychological } \\
\text { distress }\end{array}$ & 90.67 & 0.896 & 55.93 & 0.491 \\
\hline Safety to self & 93.24 & 0.929 & 72.88 & 0.589 \\
\hline Safety to others & 98.61 & 0.969 & 86.21 & 0.374 \\
\hline Alcohol & 98.44 & 0.796 & 100 & * \\
\hline Drugs & 97.14 & 0.954 & 92.59 & 0.721 \\
\hline Company & 90.54 & 0.864 & 58.62 & 0.336 \\
\hline $\begin{array}{l}\text { Intimate } \\
\text { relationships }\end{array}$ & 93.33 & 0.845 & 72.88 & 0.225 \\
\hline $\begin{array}{l}\text { Sexual } \\
\text { expression }\end{array}$ & 97.26 & 0.940 & 80.70 & 0.608 \\
\hline Child care & 90.91 & 0.862 & 56.00 & 0.231 \\
\hline Basic education & 96.00 & 0.911 & 84.75 & 0.669 \\
\hline Telephone & 95.95 & 0.919 & 79.31 & 0.289 \\
\hline Transport & 94.44 & 0.842 & 100 & * \\
\hline Money & 95.65 & 0.863 & 87.04 & 0.465 \\
\hline Benefits & 95.77 & 0.952 & 83.33 & 0.746 \\
\hline Treatment & 98.63 & 0.977 & 77.19 & 0.496 \\
\hline Sexual offences & 80.00 & 0.583 & 33.33 & 0.182 \\
\hline Arson & 100 & 1.000 & 33.33 & 0.182 \\
\hline $\begin{array}{l}\text { Kappa weighted } \\
\text { coefficient mean }\end{array}$ & & 0.884 & & 0.445 \\
\hline
\end{tabular}

below 0.4 (fair grade of agreement): "Living environment", "Information", "Safety to Others", "Company", "Intimate Relationships", "Child Care", "Telephone", and "Arson". The Kappa weighted coefficients could not be calculated in "Accommodation", "Alcohol" or "Transport" domains because the need status value was constant (100\% agreement). In the "Food" domain the Kappa weighted coefficient was not applicable due to several empty cells in the agreement table (Table 4).

\section{Convergent validity}

The correlation between CANFOR summary scores and GAF - disability scale were significantly negative (as CANFOR summary scores increased, the GAF score decreased) in all CANFOR scores, except for the "met needs" and "satisfaction" rated by FPSUs. Higher correlations were found in "unmet needs", "total needs" and "formal help needed" in both users and staff ratings (Table 5).

The correlation between CANFOR summary scores and BPRS total score revealed a significant positive correlation in "unmet needs" and "total needs" scores as rated by FPSUs, and a significant positive correlation in "unmet needs", "total needs", "formal help given" and "formal help needed" scores as rated by the staff. The users' satisfaction ratings showed no correlation with GAF or BPRS scores (Table 5).

Subsequently, tests were run on the presence of differences in the BPRS mean scores between the FPSUs with

Table 5 Correlations between CANFOR summary scores and GAF and BPRS

\begin{tabular}{|c|c|c|c|c|}
\hline & $\begin{array}{l}\text { FPSUs } \\
\text { rating } \\
\text { vs GAF } \\
(n=143)\end{array}$ & $\begin{array}{l}\text { Staff } \\
\text { rating } \\
\text { vs GAF } \\
(n=143)\end{array}$ & $\begin{array}{l}\text { FPSUs } \\
\text { rating } \\
\text { vs BPRS } \\
(\mathrm{n}=114)\end{array}$ & $\begin{array}{l}\text { Staff } \\
\text { rating } \\
\text { vs BPRS } \\
(\mathrm{n}=114)\end{array}$ \\
\hline \multirow{2}{*}{$\begin{array}{l}\text { CANFOR summary } \\
\text { scores }\end{array}$} & \multicolumn{2}{|c|}{ Spearman's rho } & \multicolumn{2}{|l|}{ Spearman's rho } \\
\hline & \multicolumn{2}{|l|}{ ( $p$ value) } & \multicolumn{2}{|l|}{ ( $p$ value) } \\
\hline \multirow[t]{2}{*}{ Met needs } & 0.009 & -0.283 & -0.033 & 0.030 \\
\hline & (ns) & $(0.001)$ & (ns) & (ns) \\
\hline \multirow[t]{2}{*}{ Unmet needs } & -0.385 & -0.323 & 0.280 & 0.232 \\
\hline & $(<0.001)$ & $(<0.001)$ & $(0.003)$ & $(0.013)$ \\
\hline \multirow[t]{2}{*}{ Total needs } & -0.334 & -0.415 & 0.261 & 0.181 \\
\hline & $(<0.001)$ & $(<0.001)$ & $(0.005)$ & (ns) \\
\hline \multirow[t]{2}{*}{ Informal help given } & -0.177 & -0.266 & 0.109 & 0.009 \\
\hline & $(0.035)$ & $(<0.001)$ & (ns) & (ns) \\
\hline \multirow[t]{2}{*}{ Formal help given } & -0.169 & -0.394 & 0.078 & 0.204 \\
\hline & $(0.043)$ & $(<0.001)$ & (ns) & $(0.030)$ \\
\hline \multirow[t]{2}{*}{ Formal help needed } & -0.333 & -0.417 & 0.169 & 0.200 \\
\hline & $(<0.001)$ & $(<0.001)$ & (ns) & $(0.033)$ \\
\hline \multirow[t]{2}{*}{ Satisfaction } & -0.026 & & 0.058 & \\
\hline & (ns) & & (ns) & \\
\hline
\end{tabular}

ns- Not statistically significant ( $p>0.05)$. 
Table 6 Significant differences in BPRS scores in FPSUs with unmet need versus without unmet need score in CANFOR domains

\begin{tabular}{|c|c|c|c|c|}
\hline & & BPRS & & \\
\hline CANFOR & User's ratings & Scales & Median & Mann-Whitney \\
\hline Domains* & $0=$ other score $(n)$ & (range: $1-7$ ) & & $U$ test \\
\hline$(n=114)$ & $1=$ unmet need $(n)$ & & & $p$ value \\
\hline \multirow[t]{2}{*}{ 1. Accommodation } & $0(110)$ & Motor hyperactivity & 1.00 & 0.001 \\
\hline & $1(4)$ & & 2.00 & \\
\hline \multirow[t]{4}{*}{ 2. Food } & $0(112)$ & Excitement & 1.00 & 0.001 \\
\hline & $1(2)$ & & 4.50 & \\
\hline & $0(112)$ & Motor hyperactivity & 1.00 & $<0.001$ \\
\hline & $1(2)$ & & 3.50 & \\
\hline \multirow[t]{4}{*}{ 5. Daytime activities } & $0(57)$ & Hallucinations & $1.00(1.25)$ & $<0.001$ \\
\hline & $1(57)$ & & $1.00(1.93)$ & \\
\hline & $0(57)$ & Unusual thought content & $1.00(1.12)$ & $<0.001$ \\
\hline & $1(57)$ & & $1.00(1.79)$ & \\
\hline \multirow[t]{2}{*}{ 6. Physical health } & $0(92)$ & Somatic concern & 1.00 & $<0.001$ \\
\hline & $1(22)$ & & 3.00 & \\
\hline \multirow[t]{10}{*}{ 7. Psychotic symptoms } & $0(101)$ & Hallucinations & 1.00 & $<0.001$ \\
\hline & $1(13)$ & & 3.00 & \\
\hline & $0(101)$ & Unusual thought content & 1.00 & $<0.001$ \\
\hline & $1(13)$ & & 3.00 & \\
\hline & $0(101)$ & Bizarre behaviour & $1.00(1.18)$ & 0.001 \\
\hline & $1(13)$ & & $1.00(2.00)$ & \\
\hline & $0(101)$ & Uncooperativeness & $1.00(1.01)$ & $<0.001$ \\
\hline & $1(13)$ & & $1.00(1.23)$ & \\
\hline & $0(101)$ & Distractibility & $1.00(1.01)$ & 0.002 \\
\hline & $1(13)$ & & $1.00(1.23)$ & \\
\hline \multirow{4}{*}{$\begin{array}{l}\text { 8. Information about condition } \\
\text { and treatment }\end{array}$} & $0(63)$ & Hallucinations & $1.00(1.32)$ & $<0.001$ \\
\hline & $1(51)$ & & $1.00(1.92)$ & \\
\hline & $0(63)$ & Unusual thought content & $1.00(1.14)$ & $<0.001$ \\
\hline & $1(51)$ & & $1.00(1.84)$ & \\
\hline \multirow[t]{6}{*}{ 9. Psychological distress } & $0(42)$ & Anxiety & $3.00(2.60)$ & $<0.001$ \\
\hline & $1(72)$ & & $3.00(3.35)$ & \\
\hline & $0(42)$ & Depression & 2.00 & $<0.001$ \\
\hline & $1(72)$ & & 4.00 & \\
\hline & $0(42)$ & Suicidality & 1.00 & $<0.001$ \\
\hline & $1(72)$ & & 2.00 & \\
\hline \multirow[t]{4}{*}{ 10. Safety to self } & $0(70)$ & Depression & 3.00 & 0.007 \\
\hline & $1(44)$ & & 4.00 & \\
\hline & $0(70)$ & Suicidality & 1.00 & $<0.001$ \\
\hline & $1(44)$ & & 4.00 & \\
\hline \multirow[t]{4}{*}{ 11. Safety to others } & $0(99)$ & Hostility & 1.00 & $<0.001$ \\
\hline & $1(15)$ & & 4.00 & \\
\hline & $0(99)$ & Tension & 1.00 & $<0.001$ \\
\hline & $1(15)$ & & 3.00 & \\
\hline \multirow[t]{2}{*}{ 13. Drugs } & $0(88)$ & Suicidality & 1.00 & 0.004 \\
\hline & $1(26)$ & & 3.50 & \\
\hline
\end{tabular}


Table 6 Significant differences in BPRS scores in FPSUs with unmet need versus without unmet need score in CANFOR domains (Continued)

\begin{tabular}{|c|c|c|c|c|}
\hline & $0(88)$ & Guilt & 2.00 & 0.003 \\
\hline & $1(26)$ & & 3.00 & \\
\hline \multirow[t]{6}{*}{ 14. Company } & $0(66)$ & Somatic concern & 1.00 & 0.005 \\
\hline & $1(48)$ & & 2.00 & \\
\hline & $0(66)$ & Motor retardation & $1.00(1.11)$ & 0.001 \\
\hline & $1(48)$ & & $1.00(1.42)$ & \\
\hline & $0(66)$ & Excitement & $1.00(1.48)$ & 0.003 \\
\hline & $1(48)$ & & $1.00(1.10)$ & \\
\hline \multirow[t]{2}{*}{ 15. Intimate relationships } & $0(69)$ & Guilt & 2.00 & 0.005 \\
\hline & $1(45)$ & & 3.00 & \\
\hline \multirow[t]{6}{*}{ 16. Sexual expression } & $0(39)$ & Guilt & 2.00 & 0.007 \\
\hline & $1(75)$ & & 3.00 & \\
\hline & $0(39)$ & Hostility & 1.00 & 0.009 \\
\hline & $1(75)$ & & 2.00 & \\
\hline & $0(39)$ & Suspiciousness & $2.00(1.77)$ & 0.009 \\
\hline & $1(75)$ & & $2.00(2.31)$ & \\
\hline \multirow[t]{2}{*}{ 19. Telephone } & $0(103)$ & Disorientation & $1.00(1.00)$ & 0.002 \\
\hline & $1(11)$ & & $1.00(1.09)$ & \\
\hline \multirow[t]{2}{*}{ 22. Social benefits } & $0(31)$ & Motor retardation & $1.00(1.00)$ & 0.002 \\
\hline & $1(83)$ & & $1.00(1.33)$ & \\
\hline \multirow[t]{4}{*}{ 23. Treatment } & $0(105)$ & Grandiosity & $1.00(1.14)$ & $<0.001$ \\
\hline & $1(9)$ & & $1.00(2.33)$ & \\
\hline & $0(105)$ & Bizarre behaviour & $1.00(1.22)$ & 0.009 \\
\hline & $1(9)$ & & $1.00(1.89)$ & \\
\hline \multirow[t]{4}{*}{ 25. Arson } & $0(110)$ & Excitement & 1.00 & 0.010 \\
\hline & $1(4)$ & & 2.00 & \\
\hline & $0(110)$ & Motor hyperactivity & 1.00 & 0.001 \\
\hline & $1(4)$ & & 1.50 & \\
\hline
\end{tabular}

* Unmet needs scores in 3.Looking after the living environment, 4.Self-care, 12.Alcohol, 14. Company, 17.Child Care, 18.Basic education, 20.Transport, 21. Money and 24.Sexual Offences domains without high significant associations with BPRS scales (>0.01). ${ }^{\mathrm{a}}$ Calculation of the mean whenever median is the same in (0) and (1) scores.

unmet need scores, as rated by themselves and staff, and the FPSUs without unmet need scores. The FPSUs with unmet needs in domains such as "Daytime Activities", "Psychotic Symptoms" and "Information about Condition and Treatment" - as rated by themselves - showed significant increased means in the BPRS scales of "Hallucinations", "Unusual Thought Content", "Bizarre Behaviour" and "Distractibility". Those with unmet needs in "Physical health", "Psychological Distress", "Safety to Self", and "Drugs" domains showed significant increased means in the BPRS scales of "Somatic Concern", "Anxiety", "Depression", "Guilt", and "Suicide", compared to FPSUs without unmet need scores. Another interesting finding was the significant increased means in "Hostility", "Tension", "Excitement", "Uncooperativeness", and "Motor hyperactivity" BPRS's scales in FPSUs with unmet needs in "Safety to Others" and "Arson" domains, compared to FPSUs without unmet needs. There was considerable similarity in the significant differences between means in the BPRS scales, according to FPSUs needs status, in both user and staff ratings. In order to minimise the problems associated with multiple testing, only the significant differences between means that attained a p value less than 0.01 are displayed in Tables 6 and 7 . The unmet needs in domains related to personal functioning and sexual abusive behaviour - "Looking after the living environment", "Self-care", "Alcohol", "Basic education", "Transport", "Money", and "Sexual Offences" - showed no differences between the means in the BPRS scale scores. Further details are available from the authors.

\section{Discussion}

Inter-rater reliability study

The CANFOR Portuguese version, which was based on the research version, showed an inter-rater reliability 
Table 7 Significant differences in BPRS scores in FPSUs with unmet need versus without unmet need score, rated by staff, in CANFOR domains

\begin{tabular}{|c|c|c|c|c|}
\hline & & BPRS & & \\
\hline CANFOR & Staff's ratings & Scales & Median & Mann-Whitney \\
\hline Domains* & $0=$ other score $(n)$ & (range: 1-7) & & $U$ test \\
\hline$(n=114)$ & $1=$ unmet need $(n)$ & & & $p$ value \\
\hline \multirow[t]{2}{*}{ 1. Accommodation } & $0(112)$ & Elated mood & 1.00 & 0.006 \\
\hline & $1(2)$ & & 3.50 & \\
\hline \multirow[t]{2}{*}{ 6. Physical health } & $0(104)$ & Somatic concern & 1.00 & 0.009 \\
\hline & $1(10)$ & & 3.00 & \\
\hline \multirow[t]{14}{*}{ 7. Psychotic symptoms } & $0(109)$ & Hallucinations & 1.00 & $<0.001$ \\
\hline & $1(5)$ & & 3.00 & \\
\hline & $0(109)$ & Unusual thought content & 1.00 & $<0.001$ \\
\hline & $1(5)$ & & 3.00 & \\
\hline & $0(109)$ & Bizarre behaviour & $1.00(1.18)$ & $<0.001$ \\
\hline & $1(5)$ & & $1.00(2.00)$ & \\
\hline & $0(109)$ & Blunted affect & $1.00(1.07)$ & $<0.001$ \\
\hline & $1(5)$ & & $1.00(1.31)$ & \\
\hline & $0(109)$ & Emotional withdrawal & $1.00(1.08)$ & 0.004 \\
\hline & $1(5)$ & & $1.00(1.15)$ & \\
\hline & $0(109)$ & Uncooperativeness & $1.00(1.01)$ & $<0.001$ \\
\hline & $1(5)$ & & $1.00(1.23)$ & \\
\hline & $0(109)$ & Distractibility & $1.00(1.01)$ & $<0.001$ \\
\hline & $1(5)$ & & $1.00(1.23)$ & \\
\hline \multirow{10}{*}{$\begin{array}{l}\text { 8. Information about condition } \\
\text { and treatment }\end{array}$} & $0(106)$ & Hallucinations & $1.00(1.32)$ & $<0.001$ \\
\hline & $1(8)$ & & $1.00(1.92)$ & \\
\hline & $0(106)$ & Unusual thought content & $1.00(1.14)$ & $<0.001$ \\
\hline & $1(8)$ & & $1.00(1.84)$ & \\
\hline & $0(106)$ & Bizarre behaviour & $1.00(1.11)$ & $<0.001$ \\
\hline & $1(8)$ & & $1.00(1.47)$ & \\
\hline & $0(106)$ & Blunted affect & $1.00(1.08)$ & 0.001 \\
\hline & $1(8)$ & & $1.00(1.12)$ & \\
\hline & $0(106)$ & Uncooperativeness & $1.00(1.03)$ & 0.001 \\
\hline & $1(8)$ & & $1.00(1.04)$ & \\
\hline \multirow[t]{4}{*}{ 9. Psychological distress } & $0(59)$ & Depression & 2.00 & 0.002 \\
\hline & $1(55)$ & & 4.00 & \\
\hline & $0(59)$ & Suicidality & 1.00 & 0.007 \\
\hline & $1(55)$ & & 2.00 & \\
\hline \multirow[t]{4}{*}{ 10. Safety to self } & $0(87)$ & Depression & 3.00 & 0.003 \\
\hline & $1(27)$ & & 4.00 & \\
\hline & $0(87)$ & Suicidality & 1.00 & $<0.001$ \\
\hline & $1(27)$ & & 4.00 & \\
\hline \multirow[t]{6}{*}{ 11. Safety to others } & $0(91)$ & Hostility & 1.00 & $<0.001$ \\
\hline & $1(23)$ & & 4.00 & \\
\hline & $0(91)$ & Tension & 1.00 & 0.001 \\
\hline & $1(23)$ & & 3.00 & \\
\hline & $0(91)$ & Excitement & $1.00(1.30)$ & 0.007 \\
\hline & $1(23)$ & & $1.00(1.47)$ & \\
\hline 13. Drugs & $0(84)$ & Suicidality & 1.00 & 0.001 \\
\hline
\end{tabular}


Table 7 Significant differences in BPRS scores in FPSUs with unmet need versus without unmet need score, rated by staff, in CANFOR domains (Continued)

\begin{tabular}{|c|c|c|c|c|}
\hline & $1(30)$ & & 3.50 & \\
\hline & $0(84)$ & \multirow[t]{2}{*}{ Guilt } & 2.00 & \multirow[t]{2}{*}{0.007} \\
\hline & $1(30)$ & & 3.00 & \\
\hline \multirow[t]{2}{*}{ 17. Child care } & $0(80)$ & \multirow[t]{2}{*}{ Anxiety } & $3.00(3.08)$ & \multirow[t]{2}{*}{0.003} \\
\hline & $1(34)$ & & $3.00(3.05)$ & \\
\hline \multirow[t]{2}{*}{ 22. Social benefits } & $0(106)$ & \multirow[t]{2}{*}{ Disorientation } & $1.00(1.00)$ & \multirow[t]{2}{*}{$<0.001$} \\
\hline & $1(8)$ & & $1.00(1.01)$ & \\
\hline
\end{tabular}

* Unmet needs scores in 3.Looking after the living environment, 4.Self-care, 5.Daytime activities, 12.Alcohol, 14.Company, 15.Intimate relationships, 16.Sexual expression, 17.Child Care, 18.Basic education, 20.Transport, 21.Money, 22.Treatment, 24.Sexual Offences and 25.Arson domains without high significant associations with BPRS scales (>0.01). Associations between unmet needs scores in 2.Food and 19.Telephone domains and BPRS scales not calculated due to variable constant. ${ }^{a}$ Calculation of the mean whenever median is the same in (0) and (1) scores.

that was very similar to the original [14] and Spanish versions [23]. Only in three domains (12\%) was the level of inter-rater agreement below 0.8 (almost perfect agreement). This high inter-rater agreement level could be due to several reasons: the ease with which the respondents understood the questions, the ease with which the raters understood the need status categories, and previous training on the instrument. In addition, the two researchers who carried out the interviews in our study had participated in the preparation of the Portuguese version of CANFOR from the beginning and shared the training on the instrument.

\section{Test-retest reliability study}

The test-retest reliability study revealed a moderate level of agreement (Kappa coefficient average between 0.40.6). The inferior test-retest reliability, compared to inter-rater reliability, could be related to rapid changes in FPSUs' opinions/perceptions caused by stress in prison or security facilities. In addition, it is understandable that mood state, anxiety and other psychopathology from FPSUs could modify their opinions/perceptions of individual needs. This difference in agreement level between inter-rater and test-retest reliability studies was also found in the original validation study [14].

\section{Convergent validity}

In previous validation studies $[14,23]$, due to the lack of other instruments suited to assessing individual need levels in a forensic setting, convergent validation was conducted with the GAF and other instruments that evaluate several aspects of disability. In the present study it was decided to use GAF - disability scale and the BPRS. The results demonstrated that individuals with more needs, especially unmet needs, rated higher scores of disability. This finding is similar to the results of other validation studies, and it shows an inverse relationship between the level of individual needs and the level of psychosocial functioning.
With regard to convergence between CANFOR and BPRS, there was a significant positive correlation of "unmet needs" and "total needs" scores, as rated by FPSUs and staff, and BPRS total scores. These results suggest a direct relationship between the level of individual unmet needs and the global psychopathology. The analysis of convergence between CANFOR domains' unmet needs and BPRS scales scores revealed interesting results. In seventeen and ten CANFOR domains, as rated by self and staff respectively, a significant higher mean score in several psychopathological scales in FPSUs with unmet needs was found (Tables 6 and 7). This was particularly evident in CANFOR domains addressing health status and behavioural risks, namely "Physical Health", "Psychotic Symptoms", "Information about Condition and Treatment", "Psychological Distress", "Safety to Self", "Safety to Others", and "Drugs". The congruence between specific domains' unmet needs and severity of psychopathology emphasizes the construct validity of CANFOR as a tool for individual care needs assessment. Moreover, these results underlined the importance of psychiatric evaluation and intervention in the general care planning directed to MDOs while detained in prison or security facilities.

\section{Strengths and limitations}

This study, which sought to assess the validity and reliability of the CANFOR Portuguese version - research version, was embedded in a broader research project that aims to evaluate the care needs in mentally ill offenders while in prison. This focus resulted in some advantages and shortcomings. Due to reasons of convenience, we chose prisons and security facilities in the Greater Lisbon area. Considering the size of the target-population, we decided to enrol all the FPSUs in a twelve month period instead of randomising them. This procedure made it possible to perform a structured assessment of both genders from different forensic psychiatric facilities (a prison psychiatric ward, prison psychiatric clinics and a civil security ward) in a 
substantial number of FPSUs. As a result the sample was heterogeneous and close to the MDO reality. In order to evaluate associations between unmet needs of care (CANFOR) and psychopathology we included the BPRS in the research protocol. However, the workload prevented the CANFOR staff reliability study. Nevertheless, we think that this limitation should be balanced taking into consideration that CANFOR reliability is not affected by the respondent status - service user or professional because in the previous studies [14,23] there have been no relevant differences of reliability data involving FPSUs or staff. To our knowledge, this is the first convergence study using these instruments in a forensic sample and the first standardized assessment of care needs in Portuguese detainees.

\section{Conclusions}

The CANFOR Portuguese version, rated by FPSUs, revealed similar psychometric properties to the original version [14]. The study of convergent validity of CANFOR with the GAF - disability scale and BPRS shows statistically significant results, which confirm that this tool is based on sound constructs and is appropriate for individual care needs assessment in this population.

The number of unmet needs differs significantly between FPSUs and staff. Although this fact is not related to the tool's reliability, it demonstrates the usefulness of CANFOR to evaluate care needs in the service user's perspective. The CANFOR Portuguese version was straightforward to administer and proved to be a reliable tool to identify clinical and social problems in FPSUs. In brief, CANFOR has the potential to be used by a range of different professionals and was considered to be a valuable tool to guide and to evaluate the health and social interventions in a mental health forensic setting.

\section{Competing interests}

The authors declare that they have no competing interests.

\section{Authors' contributions}

MT conceived the study, participated in the study design, data collection, statistical analysis and the draft manuscript. ST reviewed the manuscript and approved the CANFOR Portuguese version in order to be published. AC participated in data collection, statistical analysis and the draft manuscript. PA contributed to statistical analysis and the draft manuscript. JMCA participated in the study design and the draft manuscript. MX participated and coordinated the study design, data collection, statistical analysis and the draft manuscript. All authors read and approved the final manuscript.

\footnotetext{
Acknowledgements

This study is embedded in the larger project "Needs Assessment of the Mentally Disordered Prisoners" funded by Fundação para a Ciência e Tecnologia (PIC/IC/83257/2007). We acknowledge the General-Director for Prison Services for his authorization, the Prisons' Directors for their support, the medical and non-medical staff who collaborated in this study and detainees for their participation. Special thanks to Dr Ana Cabral for her support inside the prisons and Dr Jorge Pereira for his assistance in manuscript preparation. In memory of our late friend Dr José Morais, who collaborated on and supported this study from the beginning.
}

\section{Author details}

'CEDOC, Faculdade de Ciências Médicas, Universidade Nova de Lisboa, Campo Mártires da Pátria, Lisbon 1169-056, Portugal. ${ }^{2}$ School of Psychology \& Psychiatry, Monash University, and Victorian Institute of Forensic Mental Health, Melbourne, VIC, Australia. ${ }^{3}$ Escola Nacional de Saúde Pública, Universidade Nova de Lisboa, Lisbon, Portugal.

Received: 28 May 2012 Accepted: 9 April 2013

Published: 30 May 2013

\section{References}

1. Andersen HS: Mental health in prison populations. A review with special emphasis on a study of Danish prisoners on remand. Acta Psiquiatr Scand 2004, 110(Suppl. 424):5-59.

2. Fazel S, Danesh J: Serious mental disorder in 23000 prisoners: a systematic review of 62 surveys. Lancet 2002, 359:545-550.

3. Blaauw E, Roesch R, Kerkhof A: Mental disorders in European prison systems. Int J Law Psychiatry 2000, 23:649-663.

4. Reed J: Mental health care in prisons. Br J Psychiatry 2003, 182:287-288.

5. Mental health promotion in prisons. http://www.euro.who.int/_data/assets/ pdf_file/0007/99016/E64328.pdf.

6. Brugha $T$, Singleton $N$, Meltzer $H$, Bebbington $P$, Farrel M, Jenkins $R$, Coid J, Fryers T, Melzer D, Lewis G: Psychosis in the community and in prisons: a report from the British national survey of psychiatric morbidity. Am J Psychiatry 2005, 162:774-780.

7. Butler T, Andrews G, Allnutt S, Sakashita C, Smith NE, Basson J: Mental disorders in Australian prisoners: a comparison with a community sample. Aust N Z J Psychiatry 2006, 40:272-276.

8. Harris F, Hek G, Condon L: Health needs of prisoners in England and Wales: the implications for prison health care of gender, age and ethnicity. Health Soc Care Community 2006, 15(1):56-66.

9. Nielssen O, Misrachi S: Prevalence of psychoses on reception to male prisons in New South Wales. Aust N Z J Psychiatry 2005, 39:453-459.

10. Cohen A, Eastman N: Needs assessment for mentally disordered offenders: measurement of "ability to benefit" and outcome. Brit J Psychiatry 2000, 177:493-498.

11. Shaw J: Needs assessment for mentally disordered offenders is different. J Forensic Psychiatry 2002, 13:14-17.

12. Phelan M, Slade M, Thornicroft G, Dunn G, Holloway F, Wykes T, Strathdee G, Loftus L, McCrone P, Hayward P: The Camberwell assessment of need: the reliability and validity of an instrument to assess the needs of people with severe mental illness. Brit J Psychiatry 1985, 167:589-595.

13. Wennstrom E, Wiesel FA: The Camberwell assessment of need as an outcome measure in routine mental health care. Soc Psychiatry Psychiatry Epidemiol 2006, 41:728-733.

14. Thomas SD, Slade M, McCrone P, Harty MA, Parrott J, Thornicroft G, Leese $M$ : The reliability and validity of the forensic Camberwell assessment of need (CANFOR): a needs assessment for forensic mental health service users. Int J Methods Psychiatr Res 2008, 17(2):111-120.

15. Thomas SD, Harty MA, Parrot J, McCrone P, Slade M, Thornicroft G: Camberwell assessment of need - forensic version. London: Gaskell; 2003.

16. Relatório de actividades de 2009. Direcção Geral dos Serviços Prisionais. http://www.dgsp.mj.pt

17. Plano nacional de saúde 2004-2010: mais saúde para todos. Direcção-Geral de Saúde. http://www.dgs.pt.

18. Survey on prison populations. 2002. http://www.coe.int/t/dghl/ standardsetting/prisons/SPACEI/PC-CP(2003)5E-\%20Space-I.pdf.

19. Annual penal statistics of the council of Europe. 2009. http://www3.unil.ch/ wpmu/space/space-i/annual-reports/.

20. Relatório do plano de acção nacional para combate à propagação de doenças infecciosas em meio prisional. 2006. http://www.idt.pt/PT/IDT/ RelatoriosPlanos/Documents/2008/prisoes_infecciosaspancpdiemp.pdf.

21. Xavier M, Talina M, Morais JC: Mentally disordered persons in European prison systems - Portugal. In Treatment of mentally III in European prison systems - service provision and outcome. Edited by Salize $\mathrm{H}$, Dressing $\mathrm{H}$. Brussels: Health Protection Directorate, European Commission: 2006.

22. Duthé G, Hazard A, Kensey A, Shon JL: Suicide in prison: a comparison between France and its European neighbours. http://www.ined.fr/fichier/ t_publication/1488/publi_pdf2_pesa462.pdf.

23. Sheehan $D$, Lecrubier $Y$, Sheehan $K H$, Amorim $P$, Janavs J, Weiller $E$, Hergueta T, Baker R, Dunbar GC: The Mini International Neuropsychiatric 
Interview (MINI): the development and validation of a structured diagnostic psychiatric interview for DSM-IV and ICD-10. J Clin Psychiatry 1998, 59(Suppl. 20):22-33.

24. Black D, Arndt S, Hale N, Rogerson R: Use of the Mini International Neuropsychiatric Interview (MINI) as a screening tool in prisons: results of a preliminary study. J Am Acad Psychiatry Law 2004, 32:158-162.

25. American Psychiatric Association: Diagnostic and statistical manual of mental disorders (ed 4). Washington, DC: American Psychiatric Press; 1994.

26. Ventura J, Lukoff $D$, Nuechterlein KH, Liberman R, Green M, Schanner A: Brief Psychiatric Brief Scale (BPRS) expanded version (4.0): Scales, anchor points, and administration manual. Int J Methods Psychiatr Res 1993, 3:227-244.

27. American Psychiatric Association: Diagnostic and statistical manual of mental disorders, text revision (ed 4). Washington, DC: American Psychiatric Press; 2000.

28. Romeva GE, Rubio LG, Guerre SO, Miravet MJ, Cáceres AG, Thomas SD: Clinical validation of the CANFOR scale (Camberwell Assessment Of Need-Forensic version) for the needs assessment of people with mental health problems in the forensic services. Actas Esp Psiquiatr 2010, 38(3):129-137.

29. Altman D: Practical statistics for medical research. London: Chapman \& Hall/ Crc; 1991.

30. Fleiss J, Levin B, Paik M: Statistical methods for rates \& proportions (ed 3). New York: John Willey \& Sons Inc.; 1981.

31. Landis J, Koch G: The measurement of observers' agreement for categorical data. Biometrics 1977, 33:159-174.

doi:10.1186/1471-244X-13-157

Cite this article as: Talina et al:: CANFOR Portuguese version: validation study. BMC Psychiatry 2013 13:157.

\section{Submit your next manuscript to BioMed Central and take full advantage of:}

- Convenient online submission

- Thorough peer review

- No space constraints or color figure charges

- Immediate publication on acceptance

- Inclusion in PubMed, CAS, Scopus and Google Scholar

- Research which is freely available for redistribution 